To investigate soluble IL-2 receptor (sIL-2R) levels in nasal allergy, the sera and nasal secretions from patients with nasal allergy and from healthy subjects were subjected to a double-epitope enzyme-linked immunosorbent assay. Significant elevation of SIL-2R concentrations in the sera and nasal secretions was observed in the allergy patients $(n=26)$ compared with those of healthy subjects $(n=9)$. IL-2R-positive $\left.\left(\mathrm{CD}^{+}\right)^{+}\right)$cells were observed in the crust formed in an allergic nasal mucosa. The concentration of SII-2R in the sera correlated neither with the eosinophil count of the peripheral blood count nor with clinical severity. The concentration of SIL-2R in the nasal secretions was significantly higher compared with that in the sera from allergic patients $(p<0.01)$, whereas no significant difference was observed between sII-2R levels in the sera and nasal sections from normal subjects. These findings indicate that SIL-2R plays an essential role in allergic processes by regulating IL-2Rpositive cells recruited into the nasal mucosa.

Key words: CD25, Nasal allergy, Nasal secretion, Soluble interleukin-2 receptor

\section{Elevation of soluble interleukin-2 receptor levels in nasal allergy}

\author{
K. Hisamatsu, cA T. Ganbo, T. Nakazawa, \\ S. Horiguchi, S. Shimomura and \\ Y. Murakami
}

Department of Otorhinolaryngology, Yamanashi Medical University, 1110 Shimokato, Tamaho-cho, Nakakoma-gun, Yamanashi 409-38, Japan

CA Corresponding Author

\section{Introduction}

Nasal allergy is a typical IgE-mediated allergic inflammation of the nasal mucosa where recruitment of eosinophils, lymphocytes and mast cells, is observed. Recent studies have elucidated the role of mast cells and eosinophils in nasal allergy. However, the role of lymphocytes in this condition remains to be determined despite advances in immunological studies of cytokines and their receptors. Studies on the role of lymphocytes in nasal allergy is thus crucial for elucidation of the mechanism of allergic inflammation in the nose, since lymphocyte activation following signalling by antigen-presenting cells may initiate subsequent sequential immunological events.

Soluble IL-2 receptor (sIL-2R) is an extracytoplasmic component of the $\alpha$ chain subunit shed from the IL-2 receptor. Recently, the elevation of serum sIL-2R level has been reported in some diseases, including bronchial asthma. However, few studies have been performed on sIL-2R level in nasal allergy. In the present study, sIL-2R levels were determined in the sera and nasal secretions obtained from nasal allergy patients and from healthy control subjects.

\section{Materials and Methods}

Subjects: Twenty-six patients were diagnosed as having nasal allergy to house dust mite according to the following criteria: (1) nasal symptoms, namely persistent and recurrent nasal symptoms consisting of sneezing attacks, watery nasal discharge and nasal obstruction; (2) eosinophilia in nasal smear test; (3) positive intradermal allergen reaction; and (4) positive serum $\operatorname{IgE}$ antibody which is specific for dermatophagoides pteronyssinus, but not for pollens from trees or grass, or fungus allergens. All patients were free from other infectious and inflammatory diseases for 4 weeks, and medications were discontinued for 2 weeks before the allergological tests and collection of nasal lavage fluids. Nine normal subjects, age- and sex-matched and negative in all these allergy tests, volunteered to act as controls. The age of the patients ranged from 21 to 32 years, and the normal subjects ranged from 23 to 30 years in age. Nasal symptom scores were assessed from a symptom diary and evaluated to determine severity.

Preparation for the measurement of SIL-2R: Sera and nasal lavage fluids were collected from 26 patients with perennial nasal allergy and from nine normal subjects. Peripheral blood was extracted and immediately centrifuged twice at $1350 \times \boldsymbol{g}$ for $10 \mathrm{~min}$ at $4^{\circ} \mathrm{C}$, and the resultant sera were stored at $-80^{\circ} \mathrm{C}$ until sIL-2R level was measured.

Nasal smears were obtained prior to nasal lavage and investigated cytologically by Hansel's staining technique, ${ }^{1}$ and nasal cytograms were graded semiquantitatively. ${ }^{2}$ 
Nasal lavage was performed with $20 \mathrm{ml}$ of $0.9 \%$ saline solution with $1 \mathrm{mM} \mathrm{LiCl}$ pre-warmed to $37^{\circ} \mathrm{C}$ using a plastic syringe, and the total volume of recovered lavage fluid was measured. Suputolidin ${ }^{\circledR}$ (Boehringer Diagnostics, La Jolla, CA, USA) was mixed with nasal lavage fluid to homogenize at a volume/concentration ratio of $0.4 / 9.0$ and immediately vortexed for $1 \mathrm{~min}$, after which $5.5 \%$ Aprotinin (Sigma, MO, USA) was added at a volume/concentration ratio of $0.1 / 0.94$, followed by immediate mixing for $1 \mathrm{~min}$ at room temperature. The mixture was allowed to stand for $30 \mathrm{~min}$ at room temperature, then centrifuged at $1350 \times \boldsymbol{g}$ twice each time for $10 \mathrm{~min}$ at $4^{\circ} \mathrm{C}$, and the supernatant was stored at $-80^{\circ} \mathrm{C}$ until sIL-2R was assayed in duplicate. The lithium (Li) concentration of the nasal lavage fluid was measured by atomic emission spectrophotometry to calculate sIL-2R concentration in the nasal secretions. Li was used as an exogenous marker of nasal secretion allowing measurement from small amounts of nasal secretion. ${ }^{3}$ The sIL-2R concentration of the nasal secretion (sIL-2R $x$ ) was calculated from the following equation: sIL-2R $x=\operatorname{sIL}-2 \mathrm{Rn} \times \mathrm{LiO} /$ (Lio-Lin), where sIL-2Rn denotes the sIL-2R concentration of the sample; Lio, the Li concentration of the lavage fluid containing $0.9 \% \mathrm{NaCl}$; and $\mathrm{Lin}$, the $\mathrm{Li}$ concentration of the sample.

Measurement of sIL-2R by enzyme-linked immunosorbent assay: The double-epitope enzymelinked immunosorbent assay was used for detecting sIL-2R in the sera and nasal lavage fluids (Cellfree Interleukin-2 Receptor Bead Assay Kit ${ }^{\circledR}$, T-cell Science, MA, USA). For the measurement of sIL-2R in the nasal lavage fluids, the effect of the lavage fluid itself on the sIL-2R assay was preliminarily tested and no significant effect was found. Briefly, three nasal lavage fluid sampleswere used for the test. An equal volume of standard sIL-2R was added to each nasal lavage fluid and the actual increase in sIL-2R concentration was compared with the calculated value. The mean ( \pm S.D.) actual increase was $95 \pm 4 \%$ of the calculated value.

The assay was performed in duplicate. Briefly, 50 $\mu \mathrm{l}$ of standard or appropriately diluted serum was added to $150 \mu$ lof the horseradish peroxidase-conjugated mouse anti-human sIL-2R monoclonal antibody. One polystyrene bead coated with anti-human sIL-2R monoclonal antibody was incubated in the above mixture for $90 \mathrm{~min}$ at room temperature on a rotator set at $150 \mathrm{rpm}$. The bead was then washed three times with $2 \mathrm{ml}$ of deionized water each time. Two hundred $\mu \mathrm{l}$ of the substrate (ophenylenediamine) was added to each tube and incubated with the bead for $30 \mathrm{~min}$ at room temperature, and then $1 \mu \mathrm{l}$ of $\mathrm{H}_{2} \mathrm{SO}_{4}$ was added to stop the reaction. The solution was then decanted into a 96well flat-bottomed plate for application to an auto- matic spectrophotometer (Titerteck Multiscan ${ }^{\circledR}$ Plus MKII, Flow Laboratories Inc., CA, USA). The absorbance of the samples was measured with the spectrophotometer after setting the zero using the substrate blank. IL-2R concentration in the nasal secretion was calculated according to the above equation.

Immunocytochemical staining for $\mathrm{CD}^{2} 5^{+}$cells: Specimens of the inferior turbinate mucosa were fixed in $4 \%$ paraformaldehyde, embedded in OCT compound and frozen at $-80^{\circ} \mathrm{C}$. Fifteen $\mu \mathrm{m}$-thick sections were cut, immersed in PBS containing $0.3 \%$ Triton- $\mathrm{X}$, and incubated in methyl alcohol containing $0.3 \% \mathrm{H}_{2} \mathrm{O}_{2}$ for $20 \mathrm{~min}$ to inhibit endogenous tissue peroxidase activity. After washing in PBS, the sections were further incubated in normal goat serum for $30 \mathrm{~min}$, washed in PBS again, and then incubated overnight with mouse monoclonal anti-human CD25 antibody (Dako Ltd, High Wycombe, Buckinghamshire, UK), at a dilution of 1:400. The sections were then washed in PBS, and incubated with the biotinylated goat antimouse IgG (the second antibody, Nichirei, Tokyo, Japan) for $30 \mathrm{~min}$, washed in PBS again, and incubated with peroxidase-conjugated streptavidin for $30 \mathrm{~min}$. The reaction was then developed by treatment with diaminobenzidine for 10 min followed by washing in PBS. The sections were subsequently fixed in osmic acid solution and dehydrated before mounting.

Statistics: The Kruskal-Wallis test was used to evaluate the relationship between sIL-2R values and clinical severity. To evaluate the differences between the values of the two groups, Wilcoxon rank-sum test was used.

\section{Results}

Levels of sIL-2R in the sera: The mean ( \pm S.D.) values of serum sIL-2R concentrations in the allergic patients and of the normal subjects were $513 \pm 171 \mathrm{U} / \mathrm{ml}$ and $310 \pm 137 \mathrm{U} / \mathrm{ml}$, respectively. In patients with nasal allergy, the serum sIL-2R concentration was significantly higher as compared with that of the normal subjects $(p<0.01$, Fig. 1). However, there was no significant correlation between serum sIL-2R concentration and clinical severity.

Levels of sIL-2R in nasal secretions: The mean ( \pm S.D.) values of sIL- $2 \mathrm{R}$ concentrations in the nasal secretions of the patients and of the normal subjects were $1513 \pm 1233 \mathrm{U} / \mathrm{ml}$ and $371 \pm 193 \mathrm{U} / \mathrm{ml}$, respectively. The concentration of sIL-2R was significantly higher in the nasal secretions of nasal allergy patients compared with that of the normal subjects $(p<0.01)$. However, there was no significant correlation between the concentrations of sIL-2R in the nasal secretions and clinical severity (Fig. 2). The sIL-2R level 


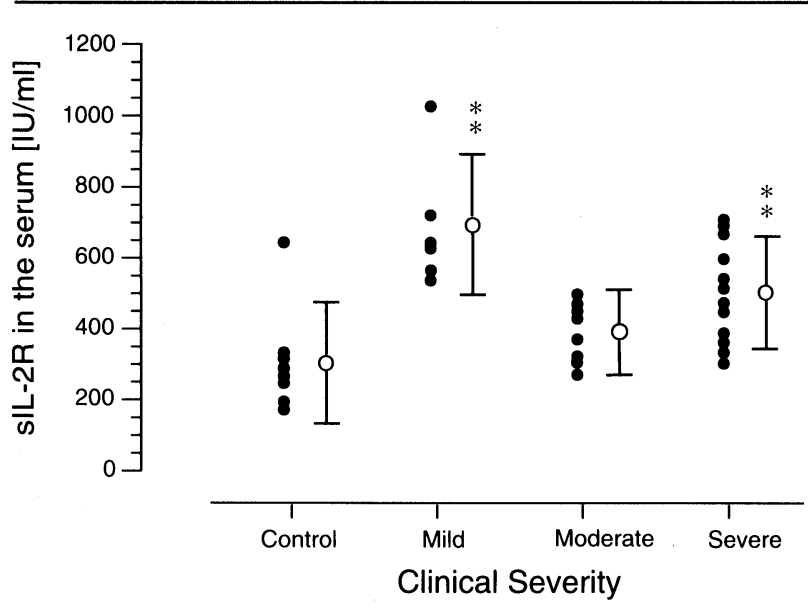

FIG. 1. Levels of serum sIL-2R and clinical severity. Elevation of serum sIL2R level was observed in nasal allergy patients $(n=26)$ compared with normal subjects $\left(n=8,{ }^{* \star} p<0.01\right)$, although there was no significant correlation between serum sIL-2R level and clinical severity.

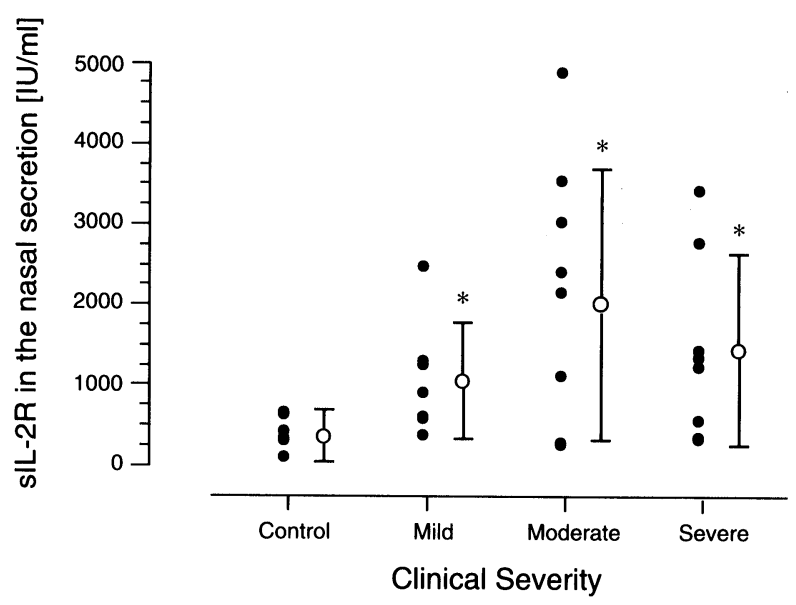

FIG. 2. Levels of SIL-2R in the nasal secretions and clinical severity. The sIL-2R level of the nasal secretions was elevated in the nasal allergy patients $(n=26)$ compared with the normal subjects $(n=9)\left({ }^{*} p<0.05\right)$. There was no significant correlation between sIL-2R concentration in the nasal secretions and clinical severity.

detected in the nasal secretions was significantly higher than that in the serum $(p<0.01)$.

Presence of $\mathrm{CD} 25^{+}$cells: $\mathrm{CD} 25^{+}$cells were found in the nasal mucosa from the inferior turbinate of nasal allergy patients (Fig. 3).

\section{Discussion}

Interleukin-2 (IL-2) is a T cell growth factor and plays a central role in the regulation of immune responses. IL-2 is released from T cells activated by IL-1 and antigen or mitogen. ${ }^{4}$ Cells responsive to IL2 include $\mathrm{T}$ cells, $\mathrm{B}$ cells, natural killer cells and macrophages/monocytes. Recent studies have shown that IL-2R has three subunits, an $\alpha$ chain, ${ }^{5}$ a $\beta$ chain, ${ }^{6}$ and a $\gamma$ chain $^{7}$. The $\alpha$ chain has a low affinity, while the combination of the $\beta$ and $\gamma$ chains shows a moderate affinity for IL-2. These three submits combine to form a high affinity IL-2R, and binding of IL-2 to IL-2R expressed on the cell membrane induces cellular activation, differentiation and proliferation. Intracellular signalling through IL-2R is

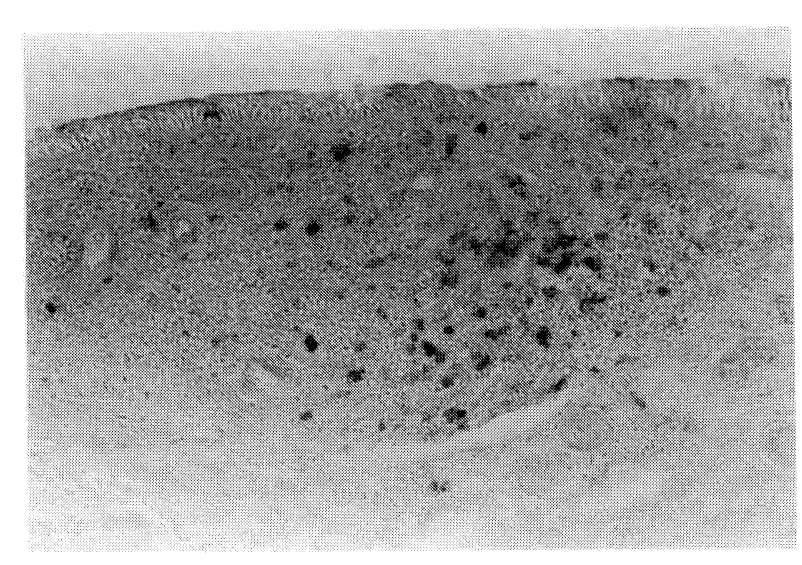

FIG. 3. Immunostaining of the nasal mucosa obtained from the inferior turbinate of a nasal allergy patient for CD25 (IL-2R). CD25+ cells formed a cluster in superficial lamina propria. (Original magnification $\times 185$.)

mediated via the associated $\beta$ and $\gamma$ subunits. The sIL$2 \mathrm{R}$ is found in the $\mathrm{T}$ cell culture medium containing a mitogen, ${ }^{8}$ and in the serum of patients suffering from diseases such as adult T cell leukaemia, Kawasaki disease,${ }^{10}$ rheumatoid arthritis, ${ }^{11}$ and bronchial asthma. ${ }^{12}$ In general, $\mathrm{T}$ cells are activated through the IL-2/IL-2R system and sIL-2R may inhibit the response of the IL-2-sensitive cells to IL-2. ${ }^{11}$ However, the role of sIL-2R in vivo still remains unclear.

In the present study, we demonstrated elevation of sIL-2R concentrations in both serum and nasal secretions, and observed infiltration of $\mathrm{CD}_{25} 5^{+}$cells in the nasal mucosa of nasal allergy patients immunocytochemically. Since CD $25^{+}$cells are not confined only to $\mathrm{T}$ cells but also include $\mathrm{B}$ cells, natural killer cells and macrophages/monocytes, sIL-2R may originate from all these cells. Thus, further studies are required to determine the cellular origin of sIL-2R in nasal allergy.

Regarding the origin of sIL-2R, an immunohistological study of the allergic nasal mucosa after exposure to allergens demonstrated a significant increase in the number of CD25+ (IL-2Rpositive) cells and $\mathrm{CD}^{+}$helper $\mathrm{T}$ cells, and showed a significant correlation between $\mathrm{CD}^{+}$and $\mathrm{CD} 25^{+}$ cells but not between macrophages and $\mathrm{CD} 25^{+}$cells. There were no changes in distribution of $\mathrm{CD} 45^{+}$cells, $\mathrm{CD}^{+}$cells or $\mathrm{CD}^{+}$cells in the nasal mucosa. A significant increase in the ratio of $\mathrm{CD}^{+} / \mathrm{CD}^{+}$ lymphocytes was observed in nasal biopsies but not in the peripheral blood after allergen challenge. ${ }^{13}$ These data strongly suggest that sIL-2R in the nasal secretion originates from helper $\mathrm{T}$ cells in the nasal mucosa.

Eosinophils are the major effector cells in the late response of allergic inflammation causing nonspecific hyperresponsiveness of the mucosa manifested by sustained clinical symptoms of nasal allergy. In the present study, we failed to find a correlation 
between serum levels of sIL-2R and peripheral blood eosinophil count, or between the levels of sIL-2R in the nasal secretions and graded eosinophilia in nasal smears. However, a significant correlation was found between serum sIL-2R and blood eosinophil count in asthmatic patients. ${ }^{12}$ Furthermore, it has also been reported that rIL-2 administration as a part of immunotherapy for a malignant tumour induced marked eosinophilia. ${ }^{14,15}$ These data still suggest a positive relationship between IL-2 and eosinophil accumulation.

The mechanism of IL-2 induced eosinophil infiltration may possibly be explained by IL- 5 derived from activated T cells. ${ }^{16,17}$ IL-5 is a potent and specific eosinophil growth factor, ${ }^{18}$ and significantly prolongs eosinophil survival. ${ }^{19}$ IL-5 also enhances the expression of adhesion molecules on vascular endothelial cells, ${ }^{20}$ and induces chemotaxis ${ }^{21}$ and activation of eosinophils. ${ }^{18}$ Therefore, CD $25^{+}$cells stimulated by IL-2 might induce eosinophil infiltration in the nasal mucosa in conjunction with IL-5 released from mast cells following allergen challenge.

In conclusion, we measured sIL-2R levels in the nasal secretions and sera from nasal allergy patients and healthy control subjects, and found elevated levels of sIL-2R concentration in both the nasal secretions and sera in the patients with nasal allergy. Accumulation of $\mathrm{CD} 25^{+}$cells was found in the allergic nasal mucosa by immunocytochemical examination. These results suggest that $\mathrm{T}$ cell activation is induced in nasal allergy, which results in persistent inflammation of the nose.

\section{References}

1. Hansel FK. Cytological diagnosis in respiratory allergy and infection. Ann Allergy 1966; 24: 564-569.

2. Krause HF. Nasal cytology in clinical allergy. In: Krause HF, ed. Otolaryngologic Allergy and Immunology. Philadelphia: WB Saunders Company, 1989; 112-122.
3. Linder A, Venge P, Deuschel H. Eosinophil cationic protein and myeloperoxidase in nasal secretions as markers of inflammation in allergic rhinitis. Allergy 1987; 42 583-590.

4. Smith KA. T-cell growth factor. Immunol Rev 1980; 51: 337-357.

5. Nikaido T, Shimizu A, Ishida N, et al. Molecular cloning of cDNA encoding human interleukin-2 receptor. Nature 1984; 311: 631-635.

6. Hatakeyama $\mathrm{M}$, Tsudo $\mathrm{M}$, Minamoto $\mathrm{S}$, et al. Interleukin-2 receptor $\beta$ chain gene: generation of three receptors from by clone human $\alpha$ chain and $\beta$ chain cDNA's. Science 1989; 244: 551-556.

7. Takeshita T, Asao H, Suzuki J, Sugamura K. An associated molecule, p64, with high affinity interleukin receptor. Int Immunol 1990; 2: 477-480.

8. Rubin LA, Kurman CC, Fritz ME, et al. Soluble interleukin-2 receptors are released from activated human lymphoid cells in vitro. J Immunol 1985; 135: 3172-3177.

9. Yasuda N, Patric K, Steohen HP, et al. Soluble interleukin 2 receptors in sera of Japanese patients with adult T cells. Blood 1988; 71: 1021-1026.

10. Lang BA, Silverman ED, Laxwe RM, Rose V, Nelson DL, Rubin LA. Serum soluble interleukin-2 receptor levels in Kawasaki disease. J Pediatrics 1990; 116: 592-596.

11. Symons JA, Wood NC, DiGiovine FS, et al. Soluble IL-2 receptor in rheumatoid arthritis. Correlation with disease activity, IL-1 and IL-2 inhibition. J Immunol 1988 141: $2612-2618$.

12. Lassalle P, Sergant M, Delneste $\mathrm{Y}$, et al. Levels of soluble IL-2 receptor in plasma from asthmatics. Correlations with blood eosinophilia, lung function, and corticosteroid therapy. Clin Exp Immuol 1992; 87: 266-271.

13. Verney VN, Jacobson MR, Sudderick RM, et al. Immunohistology of the nasal mucosa following allergen-induced rhinitis. Identification of activated $T$ lymphocytes, eosinophils, and neutrophils. Am Rev Respir Dis 1992; 146: 170-176.

14. Kovach JS, Gleich GJ. Eosinophilia and fluid retention in systemic administration of interleukin-2. J Clin Oncol 1986; 4: 815-816

15. Silberstein DS, Schoof DD, Rodrick ML, et al. Activation of eosinophils in cance patients treated with IL-2 and IL-2-generated lymphokine-activated killer cells JImmunol 1988; 142: 2162-2167.

16. Enokihara $\mathrm{H}$, Furusawa $\mathrm{S}$, Nakakubo $\mathrm{H}$, et al. $\mathrm{T}$ cell from eosinophilic patients produce interleukin-5 with interleukin-2 stimulation. Blood 1987; 73: 1809-1813.

17. Yamaguchi Y, Suda T, Shiozaki H, et al. Role of IL-5 in IL-2 induced eosinophilia in vivo and in vitro expression of IL-5 mRNA by IL-2. JImmunol 1990; 145: 873-877.

18. Lopez AF, Sanderson CJ, Gambele JR, Campbell HR, Young IG, Vadas MA Recombinant human interleukin 5 is a selective activator of human eosinophil function. J Exp Med 1988; 167: 219-224.

19. Yamaguchi $Y$, Hayashi $Y$, Sugama Y, et al. Highly purified murine interleukin 5 (IL5) stimulates eosinophil function and prolongs in vitro survival. J Exp Med 1988 167: $1737-1742$.

20. Walsh GM, Hartnell A, Wardlaw AJ, et al. IL-5 enhances the in vitro adhesion of human eosinophils, but not neutrophils, in a leukocyte integrin (CD11/18)-dependent manner. Immunology 1990; 71: 258-265.

21. Wang JM, Rambaldi A, Biondi A, Chen ZG, Sanderson CJ, Mantovani A. Recombinant human interleukin- 5 is a selective eosinophil chemoattractant. Eur $J$ Immunol 1989; 19: 701-705.

ACKNOWLEDGEMENT. This study was performed using soluble interleukin-2 recepto assay kits kindly provided from Yamanouchi Pharmaceutical Co. Ltd, Tokyo.

Received 14 September 1994; accepted in revised form 7 October 1994 


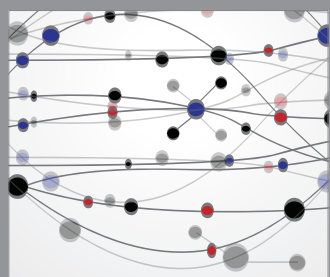

The Scientific World Journal
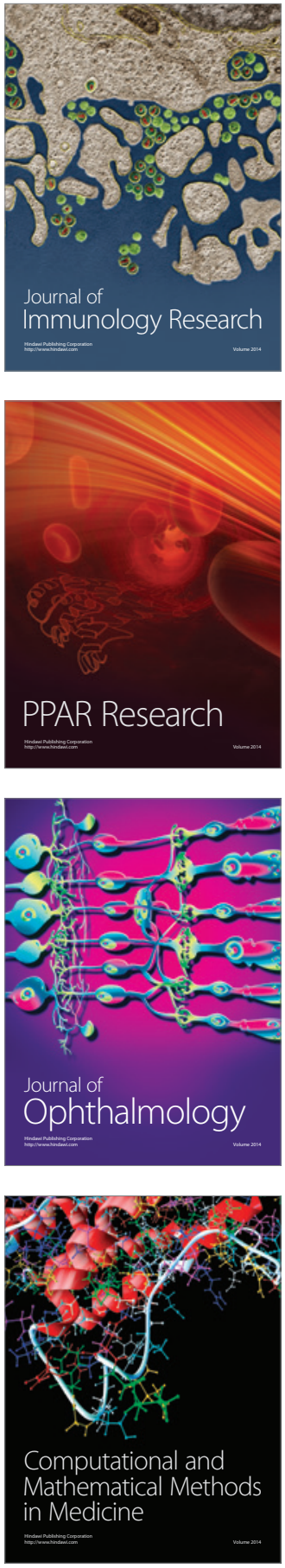

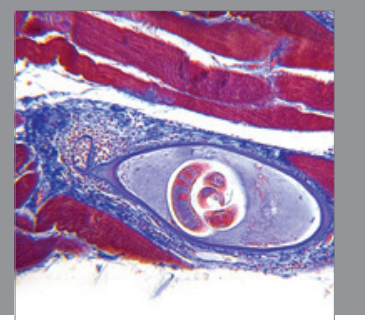

Gastroenterology

Research and Practice
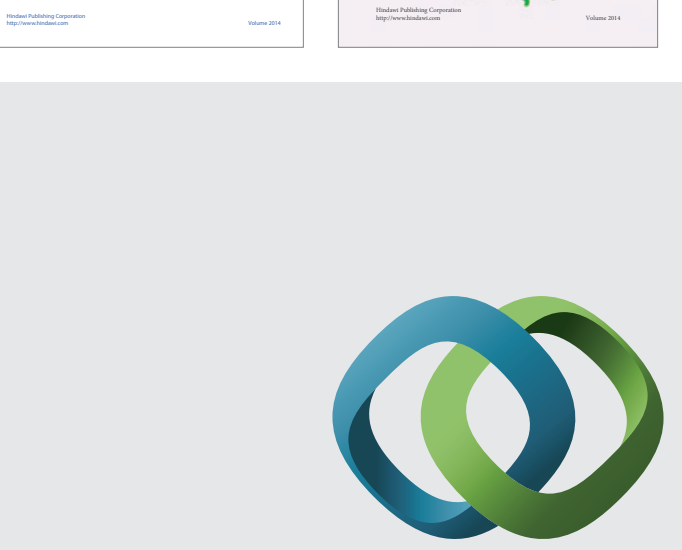

\section{Hindawi}

Submit your manuscripts at

http://www.hindawi.com
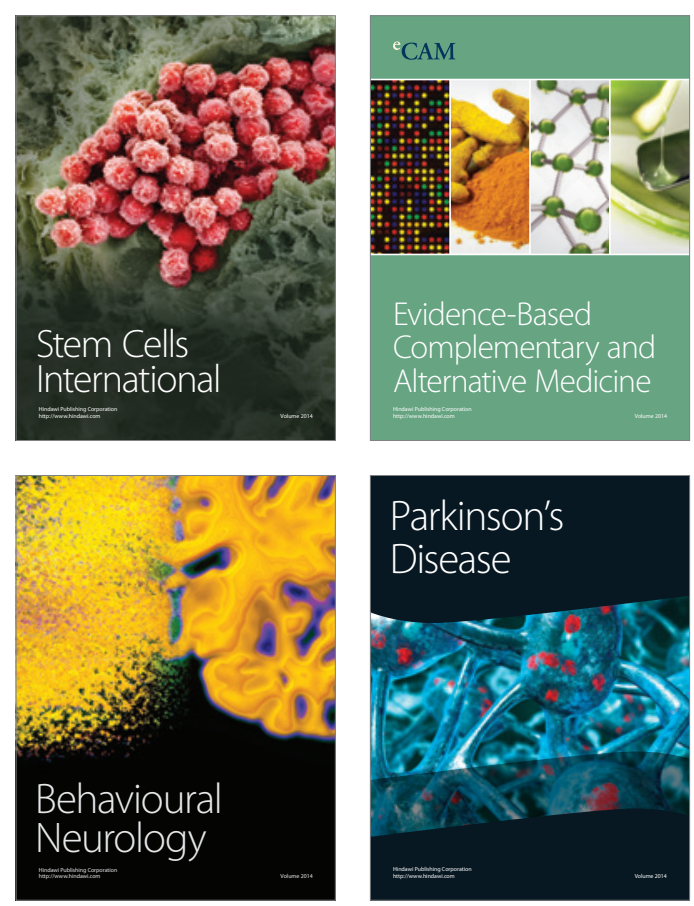

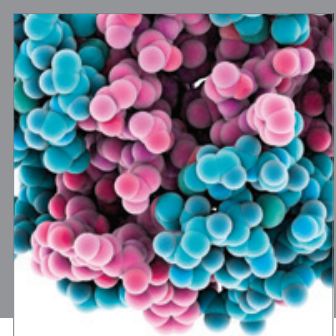

Journal of
Diabetes Research

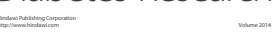

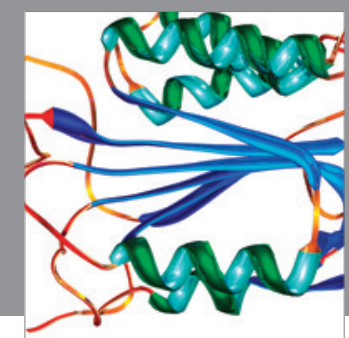

Disease Markers
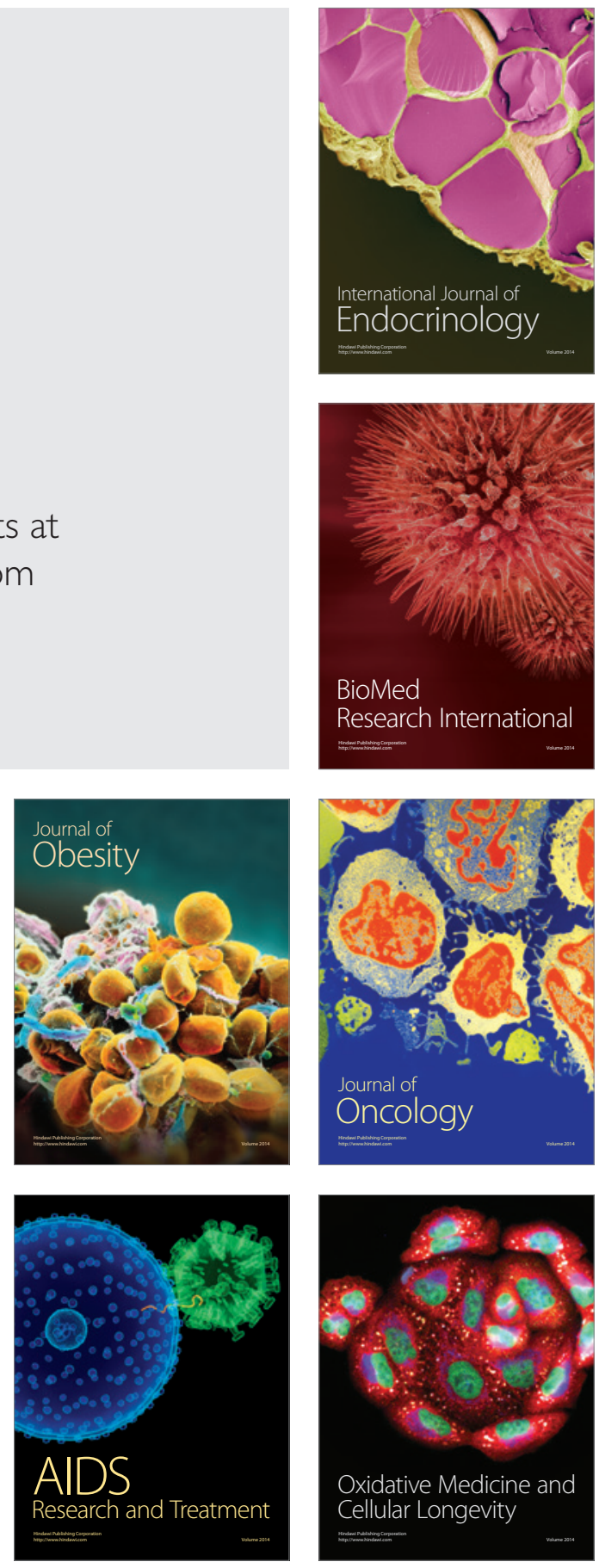